with congenital heart disease, ${ }^{4}$ the youngest previously reported case of $\mathbf{Q}$ fever endocarditis was in a 15-year-old boy with congenital subaortic stenosis, ${ }^{9}$ and 7 adults with involvement of congenital bicuspid aortic valves have also been described. ${ }^{2}$ The present case emphasises that chronic $Q$ fever infection must be considered in the differential diagnosis of infective endocarditis in childhood, particularly if there is a history of contact with farm animals and if blood cultures are negative.

We thank Dr G A K Missen and Dr M J Tynan for help and encouragement.

\section{References}

1 Powell O W, Stallman N D. The incidence and significance of phase I complement-fixing antibody in $\mathbf{Q}$ fever. J Hyg (Camb) 1962; 60: 359-64.

2 Wilson H G, Neilson G H, Galea E G, Stafford G,
O'Brien M F. Q fever endocarditis in Queensland. Circulation 1976; 53: 680-4.

3 Robson A O, Shimmin C D G L. Chronic Q fever. I. Clinical aspects of a patient with endocarditis. $\mathrm{Br} \mathrm{Med} J$ 1959; ii: $980-3$.

4 Turck W P G, Howitt G, Turnberg L A, et al. Chronic Q fever. $Q J$ Med 1976; 45: 193-217.

5 Dillon J G. Echocardiography with valvular vegetations. Am J Med 1977; 62: 856-62.

- Gottlieb S, Khuddus S A, Balooki H, Domiguez A E, Myerburg R J. Echocardiographic diagnosis of aortic valve vegetations in candida endocarditis. Circulation $1974 ; 50$ : 826-30.

7 Wray T M. The variable echocardiographic features in aortic valve endocarditis. Circulation 1975; 52: 658-63.

8 Pridie R B, Benham R, Oakley C M. Echocardiography of the mitral valve in aortic valve disease. Br Heart $J 1971$; 33: 296-304.

- Kristinsson A, Bentall H H. Medical and surgical treatment of $Q$ fever endocarditis. Lancet 1967; 2: 693-7.

Correspondence to $\mathrm{Dr} R \mathrm{~W}$ A Jones, Department of Paediatrics, Guy's Hospital, London SE1 9RT.

\title{
Facial palsy in an infant with coarctation of the aorta and hypertension
}

\author{
P MOORE AND G I FIDDLER
}

Department of Paediatric Cardiology, Killingbeck Hospital, Leeds

SUMMARY We report the unusual association of facial palsy and severe hypertension in an infant with coarctation of the aorta. The facial palsy resolved before the hypertension was cured.

\section{Case report}

A 14-week-old boy was admitted because of failure to thrive and for recoarctation after a left subclavian flap aortoplasty which had been performed for a severe isolated coarctation at age 2 weeks. The femoral pulses which had been present after surgery were absent at 10 weeks, and repeat cardiac catheterisation and angiography at 11 weeks had demonstrated the site of recoarctation and shown that left ventricular function was poor and there was a thickened left ventricular wall. On admission the infant was in mild cardiac failure and his systolic blood pressure was $200 \mathrm{mmHg}$ in the right arm and $80 \mathrm{mmHg}$ in the legs, measured by the flush method. The next day a right lower motor neurone facial palsy was noted (this was particularly obvious when he cried), with facial asymmetry and inability to close the eye. No other neurological abnormality was found and fundoscopy was normal. Despite little success in controlling blood pressure with $\beta$ receptor blockade, the facial palsy improved after 5 days and had resolved after 3 weeks. The only other treatment given was methylcellulose eye drops and a pad to close the eye. Six weeks later the coarctation was successfully repaired by inserting a Dacron bypass graft at the site of the previous aortoplasty. The blood pressure fell to $140 \mathrm{mmHg}$ (flush method) in the right arm in 4 days. Three weeks later there was a further fall to $120 \mathrm{mmHg}$. $\mathrm{He}$ remains well and is normotensive 6 months later.

\section{Discussion}

Lower motor neurone facial palsy associated with hypertension was first noted by Moxon in 1869.1 Since then the association has been described in adults and children. ${ }^{2-5}$ An incidence of between 3 and $17 \%$ has been reported, ${ }^{3-5}$ although it was not noted in a review of 100 patients. $^{6}$ All the reported cases have been associated with hypertension of a renal or idiopathic aetiology and the overall prognosis has been poor. The present case appears to be the first to be caused by hypertension 
due to coarctation of the aorta. This is probably because coarctation of the aorta accounts only for between 11 and $15 \%$ of severe childhood hypertension. ${ }^{46}$ However, the outlook with this form of hypertension is excellent, as in our patient. The pathogenesis of the facial palsy is unknown but haemorrhage ${ }^{13}$ or oedema in the facial canal may be important factors. As in this case the prognosis for the palsy is good.

In conclusion, lower motor neurone facial palsy in childhood may be associated with significant hypertension and the blood pressure should be recorded in any child with a facial palsy.

We thank Dr David Sumner for constructive criticism, and Dr Olive Scott for permission to report this case.

\section{References}

1 Moxon W. Apoplexy into canal of Fallopius in a case of Bright's disease, causing facial paralysis. Transcript Pathol Soc London 1869; 20: 420-2.

2 McMichael J. Reorientations in hypertensive disorders. Br Med J 1961; ii: 1239-44, 1310-4.

3 Lloyd A V C, Jewitt D E, Lloyd Still J D. Facial paralysis in children with hypertension. Arch Dis Child 1966; 41 : 292-4.

4 Lloyd Still J, Cottom D. Severe hypertension in childhood. Arch Dis Child 1967; 42: 34-9.

5 Rance C P, Arbus M D, Balfe K W, Koon S W. Persistent systemic hypertension in infants and children. Pediatr Clin North Am 1974; 21: 801-24.

- Gill D G, Mendes da Costa B, Cameron J S, Joseph M C, Ogg C S, Chantler C. Analysis of 100 children with severe and persistent hypertension. Arch Dis Child 1976; 51: 951-6.

Correspondence to Dr G I Fiddler, Department of Paediatric Cardiology, Killingbeck Hospital, York Road, Leeds LS14 6UQ. 